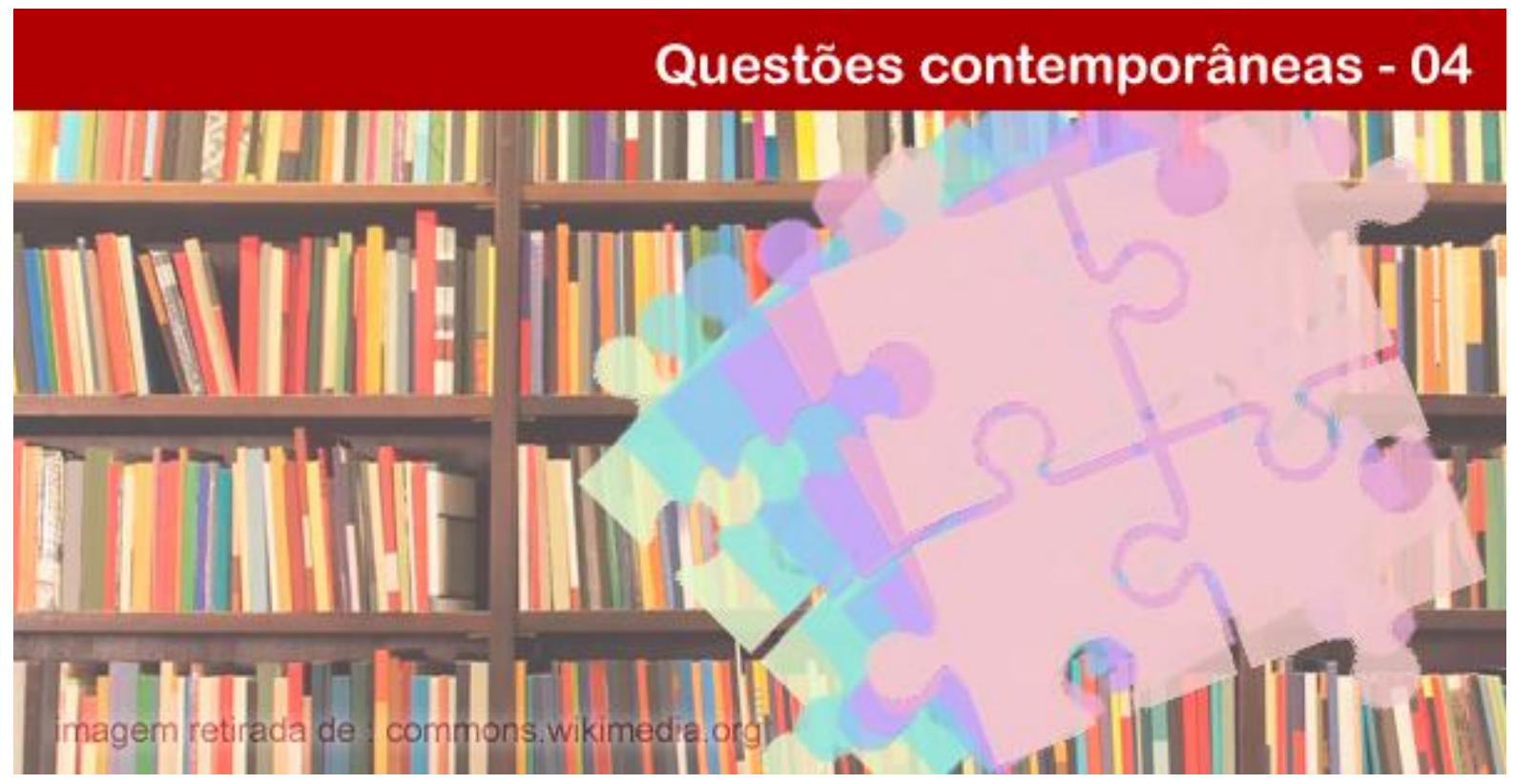

\title{
A INTERDISCIPLINARIDADE NA PRÁTICA DOS EDUCADORES SOCIAIS DO PROGRAMA DE CRIANÇA PETROBRAS
}

\section{Francisco das Chagas Silva Souza}

Doutor em Educação pela Universidade Federal do Rio Grande do Norte (UFRN). Professor do Programa de Pós-Graduação em Educação Profissional do Instituto Federal de Educação, Ciência e Tecnologia do Rio Grande do Norte (PPGEP/IFRN) e do Programa de Pós-Graduação em Ensino (IFRN/UERN/EFERSA). Email: chagas.souza@ifrn.edu.br.

\section{Kardenia Almeida Moreira}

Licenciada em Pedagogia pela Universidade do Estado do Rio Grande do Norte (UERN) e Mestranda do Programa de Pós-Graduação em Educação Profissional do Instituto Federal de Educação, Ciência e Tecnologia do Rio Grande do Norte (PPGEP/IFRN). E-mail: kardeniaam@hotmail.com.

\section{Milene Rejane Pereira}

Licenciada em Pedagogia pela Universidade do Estado do Rio Grande do Norte (UERN), Especialista em Educação e Contemporaneidade pelo Instituto Federal de Educação, Ciência e Tecnologia do Rio Grande do Norte (IFRN), Mestranda do Programa de Pós-Graduação em Educação pela Universidade do Estado do Rio Grande do Norte (UERN). E-mail: milene_rejane@hotmail.com.

Resumo: O Programa de Criança Petrobras (PCP) é um projeto social destinado a crianças e adolescentes que vivem em situação de vulnerabilidade social. Seu trabalho educativo é desempenhado por educadores sociais pertencentes a várias áreas do conhecimento, compondo uma prática que visa a interdisciplinaridade. $\mathrm{O}$ objetivo deste artigo é discutir como ocorrem as práticas desses educadores com esse fim. Quanto à metodologia, utilizou-se a pesquisa bibliográfica e a análise documental do plano de trabalho do PCP, como também relatórios escritos pelos educadores. Os documentos revelam que o planejamento de ações socioeducativas, fundamentadas numa proposta interdisciplinar, a partir de questões que envolvem o cotidiano de seus participantes, permite que estes aprendam e integrem conteúdos de forma não fragmentada. Desse modo, a educação não-formal tem se mostrado uma prática legítima e necessária diante dos desafios que envolvem a sociedade, complementando o trabalho da escola na formação de cidadãos.

Palavras-chave: Interdisciplinaridade. Educação Não-Formal. Educação Social.

\section{POLÊM!CA $\mid$ LABORE (}

Polêmica - Revista Eletrônica da Uerj - Rua São Francisco Xavier, 524, $1^{\circ}$ andar bloco D, sl.1001 • Tels.: +55 21 2334-4088/4087 • http://www.e-publicacoes.uerj.br/index.php/polemica/index http://www.labore.uerj.br • laboreuerj@yahoo.com.br 


\title{
THE INTERDISCIPLINARY PRACTICE OF SOCIAL EDUCATORS AT THE CHILDREN PROGRAMME AT PETROBRAS
}

\begin{abstract}
The Petrobras Children Programme (PCP) is a social Project directed to children and teenagers that live in a vulnerable social situation. Its educational work is developed by social educators from various knowledge fields resulting in a practice that aims at interdisciplinary actions. The objective of this article is discussing how these practices occur. The methodology used bibliographical research and documental analysis from the work plan of the PCP, as well as the educators' written reports. The documents revealed that the planning of social educational actions, based on an interdisciplinary approach, from questions involving the participants' daily life, allow them to learn and integrate contents in a non-fragmented approach. Thus, nonformal education has been a legitimate and necessary practice before the challenges involving society, completing on the school work on the citizens' formation.
\end{abstract}

Keywords: Interdisciplinarity. Non-Formal Education. Social Education.

\section{Introdução}

$\mathrm{Na}$ atualidade, em função das transformações no mundo do trabalho, do avanço das novas tecnologias, das mudanças na instituição familiar, dentre outros fatores, tem emergido novas necessidades educacionais que estão além do espaço escolar. Logo, a articulação entre a educação, em seu sentido mais amplo, com processos formativos de cidadania, passou a se constituir, não em utopia, mas em uma necessidade iminente diante das demandas que emergem na sociedade (GOHN, 2010).

Diante dessas demandas, ações complementares se tornam necessárias e ocorrem por meio de projetos socioeducativos que visam contribuir, por exemplo, para o desenvolvimento integral de crianças e adolescentes. São intervenções realizadas a partir de políticas públicas, movimentos sociais, Organizações Não-Governamentais, instituições públicas e privadas, dentre outros agentes.

De acordo com Gohn (2010), a educação não-formal, ao abrir janelas de conhecimentos sobre o contexto que envolve os indivíduos e suas relações sociais, tem o objetivo de capacitá-los para que estes se tornem cidadãos do mundo, no próprio mundo. Para a autora, essa educação ocorre em ambientes em que se desenvolvem situações interativas construídas pelo grupo, possuindo, em suas ações, uma intencionalidade no que se refere ao ato de aprender, ensinar, participar ou simplesmente a troca saberes. Neste sentido, ela desenvolve laços de pertencimento e auxilia na construção identitária coletiva do grupo envolvido.

Quando se voltam para a proteção à criança e ao adolescente, essas ações visam erradicar o trabalho e a exploração infanto-juvenil, legitimando direitos que foram estabelecidos pelo Estatuto da Criança e do Adolescente na década de 1990. Portanto, são

\section{POLÊM!CA $\mid$ LABORE}

Polêmica - Revista Eletrônica da Uerj - Rua São Francisco Xavier, 524, $1^{\circ}$ andar

bloco D, sl.1001 • Tels.: +55 21 2334-4088/4087 • http://www.e-publicacoes.uerj.br/index.php/polemica/index

http://www.labore.uerj.br • laboreuerj@yahoo.com.br 
medidas que asseguram a ampliação das possibilidades educacionais, culturais e sociais ao ocupar o tempo livre desses sujeitos.

Neste artigo, são discutidas as práticas de educadores sociais no Programa de Criança Petrobras (doravante PCP), em Mossoró-RN, buscando identificar como, nessas atividades, perpassa uma perspectiva interdisciplinar. Isso se justifica pela importância que a interdisciplinaridade tem ao propor um trabalho integrador e dialógico na construção do conhecimento e da prática pedagógica, convergindo com os objetivos da educação nãoformal. O recorte temporal será o período de 2007 a agosto de 2011, quando o PCP contou com a participação da Universidade do Estado do Rio Grande do Norte (UERN) ${ }^{1}$. A pesquisa se restringiu às ações do PCP em Mossoró em face de neste município se encontrar o Campus Central da UERN, facilitando assim o acesso às informações para os pesquisadores.

Com base no objetivo do estudo, este artigo está dividido em duas partes. Inicialmente, é apresentada uma revisão bibliográfica acerca da educação não-formal e os desafios que ela enfrenta para pôr em prática os seus princípios norteadores.

Na segunda parte deste texto, são examinados os documentos do plano de trabalho do PCP, em Mossoró-RN, cuja elaboração contou com a participação da Faculdade de Educação da UERN. Também foram considerados na pesquisa, os relatórios disponibilizados pelos educadores. Nessa análise documental, além de descrever um breve histórico do projeto, seguido pela sua finalidade, discorre-se ainda sobre a metodologia desenvolvida pelo PCP, focadas em ações socioeducativas de caráter interdisciplinar.

\section{Educação não-formal: emergência e desafios}

Até a década de 1980, a educação não-formal, no Brasil, estava ligada a processos de alfabetização de adultos (GOHN, 1999) e tinham como base as propostas educativas de Paulo Freire, bem como as práticas de movimentos sociais que auxiliavam na formação profissional de adultos.

A concepção de educação não-formal apresentada neste artigo se articula ao campo da educação cidadã, visto que associa-se a processos de inclusão social desenvolvidos em comunidades carentes, possibilitando o acesso a conhecimentos que, durante gerações,

\footnotetext{
${ }^{1}$ Destaca-se que, de agosto de 2011 a fevereiro de 2013, o projeto ficou suspenso, aguardando autorização de recursos para que assim fosse assinado um novo convênio com a UERN. Em 2013, o PCP voltou a funcionar, mas sem a participação da UERN. Entretanto, desde 2014, o PCP se encontra com suas atividades interrompidas e aguarda a solução de questões burocráticas para a assinatura de um novo convênio.
}

\section{POLÊM!CA $\mid$ LABORE}


estiveram à disposição apenas dos setores hegemônicos da sociedade. Assim, no contexto brasileiro, a educação não-formal está inserida no conjunto das novas práticas educativas propostas por educadores e pelos movimentos sociais organizados.

Pode-se afirmar, com base em Severo e Pimenta (2015), que a educação não-formal emerge no contexto das novas configurações pedagógicas que caracterizam a sociedade contemporânea, marcada pela pluralidade de demandas e novas configurações em torno dos processos de ensinar e aprender. Os autores destacam que a sociedade precisa despertar para necessidades e desejos de ensino e aprendizagem, além de estabelecer dimensões pedagógicas nas relações sociais que lhe são constitutivas.

Para Gadotti (2005), a educação formal está bem representada nas escolas e universidades, tendo, como diretriz educacional, uma centralização no currículo com a presença de estruturas hierárquicas e burocráticas, determinadas, em nível nacional, por órgãos fiscalizadores do Ministério da Educação. No entanto, a educação não-formal é menos hierárquica e burocrática, e, portanto, mais difusa.

Reconhecendo a existência de práticas educativas em espaços formais, não-formais e informais, Libâneo (2010) vai além da concepção de educação como algo limitado às instituições escolares, compreendendo-a como "o conjunto das ações, processos, influências, estruturas que intervêm no desenvolvimento humano de indivíduos e grupos na sua relação ativa com o meio natural e social, num determinado contexto de relações entre grupos de classes sociais" (p. 30).

Ao trazer essa definição, o autor permite perceber a educação como uma prática social humana, individual e coletiva, pois auxilia o indivíduo a refletir não apenas para o seu pensar, mas também o seu existir e o seu fazer. Sob esse ponto de vista, não se pode restringir a educação como algo apenas do âmbito escolar, pois, sem fronteiras, ela se estende para além desse espaço e necessita humanizar as relações que se configuram na sociedade.

Para Gohn (2006) a educação não-formal designa um processo com várias dimensões, dentre elas estão: a aprendizagem política dos direitos dos indivíduos enquanto cidadãos; a capacitação para o trabalho; a aprendizagem e exercício de práticas coletivas com objetivos comunitários na solução de problemas; a aprendizagem de conteúdos que possibilitem uma leitura de mundo; a educação desenvolvida na mídia e pela mídia, em especial a eletrônica. Neste sentido, a autora apresenta como finalidade da educação não-formal a possibilidade de

\section{POLÊM!CA $\mid$ LABORE}


conhecer o mundo: "Ela prepara os cidadãos, educa o ser humano para a civilidade, em oposição à barbárie, ao egoísmo, individualismo etc.” (GOHN, 2006, p. 29-30).

Enquanto a educação formal ocorre em ambientes que pressupõem regras e padrões definidos como a escola, onde o educador é o professor, a educação não-formal, por sua vez, ocorre em espaços onde as interações se constroem coletivamente, segundo as diretrizes estabelecidas pelas finalidades do próprio grupo. Aqui, o educador é o outro, ou seja, é aquele com quem interage ou se integra no compartilhamento de experiências (GOHN, 2006).

Na educação não-formal, o educador, além de se dedicar à causa da educação social, precisa desenvolver a capacidade de criar conexões entre a realidade social e a aprendizagem e proporcionar a autoestima dos indivíduos intervencionados. Entretanto, para que isso ocorra, o educador social também precisa saber interpretar essa realidade social e lidar com as variadas formas de preconceito e de discriminação presentes nela.

Considerando esse cenário onde se criam e recriam inúmeras possibilidades de aprender e de ensinar com base nas vivências dos sujeitos, abordam-se a seguir as práticas desenvolvidas no PCP. Este programa é financiado integralmente pela empresa Petrobras e recebeu, entre os anos de 2006 a 2011, o apoio pedagógico da Universidade do Estado do Rio Grande do Norte para a capacitação dos educadores sociais. Todavia, importa destacar que, somente a partir de 2007, o PCP passou a utilizar uma perspectiva metodológica pautada na interdisciplinaridade, fato que justifica o recorte temporal de 2007 a 2011.

\section{O perfil educativo do Programa de Criança Petrobras (PCP)}

O PCP foi criado pela Petrobras, em 1983, no Rio de Janeiro, e se expandiu nos municípios brasileiros onde essa empresa atua. O Programa é uma ação educativa e social que utiliza atividades de caráter educacional, artístico-cultural e de esporte e lazer.

No estado do Rio Grande do Norte, o PCP foi implantado inicialmente em Natal, em 1996, seguido pelos municípios de Macau (1998), Mossoró (2000), Guamaré (2005), Nova Parnamirim, Assú e Alto do Rodrigues (2008) e Areia Branca (2011).

O objetivo do PCP, em Mossoró, pode ser encontrado no documento elaborado pela Petrobras:

Contribuir para a melhoria da qualidade de vida e ampliar o campo das possibilidades educacionais, culturais e existenciais de 150 crianças e adolescentes matriculados em escolas públicas no município de Mossoró/RN, proporcionando-

\section{POLÊM!CA $\mid$ LABORE}


lhes a possibilidade de construção de um projeto de vida, fundamentado em valores e princípios éticos e de cidadania (PETROBRAS, 2008, p. 05).

As 150 crianças e adolescentes a que se refere o documento da Petrobras tinham idade entre sete e dezesseis anos e onze meses e eram matriculados regularmente na rede pública de ensino de Mossoró-RN. O projeto era realizado no Clube dos Empregados da Petrobras (CEPE/Mo) e atendia os bairros Aeroporto II, Quixabeirinha e Belo Horizonte, localizados em áreas periféricas desse município.

O PCP também orienta que essas crianças e adolescentes deveriam ser selecionados entre aqueles que enfrentavam problemas de relacionamento interpessoais: crianças com baixo rendimento escolar e adolescentes que apresentem comportamentos avessos ao esperado na escola. Portanto, alunos que se constituem em "um problema" para a escola regular.

Assim, por se caracterizar como um projeto socioeducativo, as ações do PCP eram complementares às atividades escolares e conjugavam educação e proteção às crianças e adolescentes em situação de risco social. Tais atividades ocorriam nos turnos inversos da escola, objetivando o desenvolvimento integral desses sujeitos.

Em 2006, a UERN, por meio da Pró-Reitoria de Extensão, inseriu a Faculdade de Educação num convênio com a Petrobras e o Clube dos Empregados da Petrobras, passando a assumir a responsabilidade pedagógica do PCP sob a direção de um de seus professores. Este ficaria encarregado de selecionar profissionais formados para a coordenação pedagógica e estagiários de diversas licenciaturas daquela universidade: Pedagogia, Letras, Matemática, Educação Física, Geografia, Química. A opção por uma equipe multidisciplinar facilitou o desenvolvimento de uma proposta interdisciplinar como metodologia do projeto.

Vale salientar que esta parceria possibilitou mudanças significativas na concepção pedagógica e na metodologia de trabalho do PCP, pois antes o foco das ações educativas se limitava apenas a aula de reforço escolar. Durante o ano de 2006, a orientação pedagógica se dedicou a conhecer e analisar a filosofia do PCP para, então, propor o modelo pedagógico que passou a vigorar a partir de 2007. Com a participação acadêmica da UERN, as atividades receberam maior contribuição teórica, fomentado a perspectiva interdisciplinar nas ações educativas desenvolvidas pelos seus educadores sociais. Dessa maneira, os objetivos presentes no plano de trabalho se ampliaram.

\section{POLÊM!CA $\mid$ LABORE}


Atendendo ao foco deste artigo, selecionou-se aqueles que mais se aproximavam das práticas educativas interdisciplinares:

- Fornecer, às crianças de Mossoró, instrumentos teóricos e metodológicos que as capacitem a construir/resolver problemas em diferentes áreas do saber.

- Estimular a capacidade investigativa das crianças, tornando-as capazes de buscar o conhecimento em diferentes campos.

- Desenvolver práticas educativas que utilizem o conhecimento científico para a realização de leituras sobre a comunidade e o seu cotidiano.

- Possibilitar que as crianças possam vivenciar o esporte, o lazer, a cultura, associados a um projeto de conhecimento contínuo.

- Promover atividades regulares que tenham por meta trazer para o Programa a família e as escolas das crianças.

- Acompanhar o desenvolvimento escolar das crianças em suas escolas regulares, identificando o perfil sociocultural das mesmas.

Percebe-se que os objetivos do PCP evidenciavam a preocupação em superar os limites que, muitas vezes, são encontrados na produção do conhecimento e, consequentemente, nos processos educativos e de socialização.

No trabalho educativo, o que se designa por interdisciplinaridade é uma atitude epistemológica que ultrapassa os hábitos intelectuais estabelecidos ou mesmo os programas de ensino já consolidados (FAZENDA, 1993). As leituras em Freire (1987) conduzem a perceber a interdisciplinaridade como um processo metodológico na construção do conhecimento pelo próprio sujeito a partir das interações socioculturais, num movimento dialético entre uma situação que desvela a realidade de um lado, e, do outro, a sistematização desses conhecimentos integradamente.

Segundo Fazenda (1993), o pensar interdisciplinar parte da premissa de que nenhuma forma de conhecimento é em si mesma racional. Tenta, pois, o diálogo com outras formas de conhecimento, deixando-se interpenetrar por elas. Aceita o conhecimento do senso comum como válido, pois é a partir do cotidiano que é dado sentido à vida.

Já em conformidade com os Parâmetros Curriculares Nacionais do Ensino Médio:

\section{POLÊM!CA $\mid$ LABORE}


[...] a interdisciplinaridade supõe um eixo integrador, que pode ser o objeto de conhecimento, um projeto de investigação, um plano de intervenção. Nesse sentido, ela deve partir da necessidade sentida pelas escolas, professores e alunos de explicar, compreender, intervir, mudar, prever, algo que desafia uma disciplina isolada e atrai a atenção de mais de um olhar, talvez vários. Explicação, compreensão, intervenção são processos que requerem um conhecimento que vai além da descrição da realidade mobiliza competências cognitivas para deduzir, tirar inferências ou fazer previsões a partir do fato observado (BRASIL, 2002, p. 88-89).

Desta forma, a metodologia proposta pelos educadores sociais, no PCP, visava propiciar ações em que as crianças e os adolescentes fossem capazes de produzir algo que os possibilitasse a descoberta e a construção de conhecimentos envolvendo diferentes campos dos saberes, além de publicar suas produções, interagir com outros sujeitos e intervir na comunidade. A partir de então, o PCP passou a ser estruturado em dois núcleos denominados Núcleo de corpo, esporte e lazer e Núcleo de artes visuais, sonoras e cênicas.

Os núcleos eram formados por uma equipe multidisciplinar. O Núcleo de corpo, esporte e lazer era responsável pela orientação das atividades de abordagem corporal, sob a perspectiva lúdica, envolvendo ações esportivas, de lazer e recreação, com o objetivo de explorar as noções de espaço, tempo, lateralidade, coordenação motriz, velocidade, intensidade, cooperação, regras de convivência, conhecimento e percepção sobre o corpo em relação a si mesmo e ao outro. Já o Núcleo de artes visuais, sonoras e cênicas estava voltado para a orientação das atividades artísticas, na perspectiva da criação livre e dirigida, envolvendo expressões musicais, dramáticas, coreográficas, visuais e plásticas (PETROBRAS, 2008).

As habilidades de comunicação e de expressão estética eram trabalhadas diretamente pelos núcleos por meio das linguagens orais, corporais, imagéticas e sonoras. Em suas produções, eram valorizados: a criatividade, a imaginação e a fantasia, o trabalho em equipe, a expressão com a fala, o corpo, o olhar, a escrita, a pintura e a música. O trabalho, como um todo, visava aprendizagens sobre o tempo, o espaço, a luz, a cor, o som, o corpo, a voz, os materiais e as tecnologias (PETROBRAS, 2008).

O trabalho dos núcleos era orientado por um tema geral e, a partir deste, ocorria a elaboração dos projetos de investigação aos quais os núcleos deveriam se articular sem perder de vista o desenvolvimento cognitivo, emocional, afetivo e cultural do público atendido. A temática geral que definia o trabalho dos núcleos era escolhida a partir do interesse das crianças e dos adolescentes e das possibilidades de investigação e orientação dos profissionais

\section{POLÊM!CA $\mid$ LABORE}


e estagiários envolvidos no PCP. Levavam-se em conta, portanto, as orientações de Fazenda (2013):

\begin{abstract}
Um projeto interdisciplinar de trabalho ou de ensino consegue captar a profundidade das relações conscientes entre pessoas e entre pessoas e coisas. Nesse sentido, precisa ser um projeto que não se oriente apenas para o produzir, mas que surja espontaneamente, no suceder da vida, de um ato de vontade. Nesse sentido, ele nunca poderá ser imposto, mas deverá surgir de uma proposição, de um ato de vontade frente a um projeto que procura conhecer melhor. (FAZENDA, 2013, p. 20, grifos da autora).
\end{abstract}

Entre os anos 2007 a 2011, período de implementação dessa proposta de trabalho, o PCP desenvolveu vários projetos educativos: Brinquedos e brincadeiras, Lixo, $\mathrm{O}$ alimento nosso de cada dia, Aprender com Arte, ECA: todo direito tem um dever.

Mas de que formas o trabalho pedagógico era desenvolvido pelos educadores sociais no PCP? Como a interdisciplinaridade fazia-se presente nos projetos e atividades propostas?

De acordo com os documentos oficiais do PCP, o trabalho pedagógico pretendido deveria permitir às crianças e aos adolescentes "a condição de desenvolver a capacidade de pensar, produzir, publicar interagir e intervir na comunidade" (PETROBRAS, 2008, p. 10). Obviamente, isso se configurava em um desafio para os educadores sociais que orientavam o trabalho junto ao público atendido pelo programa, tendo em vista que, para desenvolver um trabalho na perspectiva da interdisciplinaridade, faz-se necessário partir de uma problemática de interesse geral, para utilizar as diferentes áreas do conhecimento como ferramentas para compreender e/ou "solucionar" problemas. Isso equivale a romper com um modelo disciplinar de educação que ainda é predominante.

Também entre os desafios que envolvem um trabalho dessa natureza, estava a formação da equipe pedagógica para o desenvolvimento desses projetos. Para tanto, o plano de trabalho previa encontros de capacitação, por meio das Jornadas Pedagógicas, com a participação de professores da UERN, pertencentes a diversas áreas, o intercâmbio com outras instituições de ensino, grupos de pesquisa, leituras, visitas a museus, bibliotecas, exposições e troca de experiências com outros programas, além dos encontros semanais para avaliação e planejamento. Todas as ações formativas se voltavam para a compreensão da interdisciplinaridade, superando a prática disciplinar de acúmulo de informações.

A Jornada Pedagógica consistia no ponto de partida e ocorria antes do início das atividades com as crianças e os adolescentes. Eram nesses encontros que se definiam os temas

\title{
POLÊM!CA $\mid$ LABORE
}


geradores dos projetos, definindo a problemática, os objetivos, as metas, a metodologia, as atividades, o cronograma de trabalho e a bibliografia. Em seguida, ocorriam estudos para subsidiar o trabalho dos educadores sobre os temas a serem investigados. As outras atividades do PCP (apresentações culturais, eventos, palestras, passeios ecológicos) eram planejadas de forma a manter uma relação estreita com a produção de conhecimento orientada nos projetos.

As ações educativas do projeto eram realizadas por meio de oficinas que se subdividiam em: oficinas de intervenção pedagógica, responsáveis pelos projetos de investigação e as produções desenvolvidas pelas crianças e adolescentes; oficinas esportivas, encarregadas por focalizar o conhecimento do corpo humano e proporcionar o desenvolvimento das habilidades físicas dos participantes, estabelecendo vínculos com os projetos de investigação desenvolvidos; e as oficinas de arte-educação, com a incumbência do ensino de dança, teatro, música e artes plásticas, com o intuito de desenvolver, nas crianças e adolescentes, atitudes de respeito à diversidade de expressões artísticas, visto que geralmente os resultados dos projetos de investigação eram transformados em apresentações artísticoculturais (PETROBRAS, 2008).

Todas as crianças e adolescentes participavam de forma alternada dessas oficinas em grupos. Estes, por sua vez, eram organizados aleatoriamente e possibilitavam a interação entre os participantes de diferenças de idade, gênero e níveis de aprendizagem, pois se acreditava que essa comunicação propiciaria a troca de experiências, favorecendo assim a aprendizagem.

Considera-se que essa organização dos grupos condiz com as características da educação não-formal apresentadas por Gohn (2006), pois, para ela, dentre os atributos deste tipo de educação está a não organização por séries, idade e/ou conteúdos. Assim, para ela, a educação não-formal:

[...] trabalha e forma a cultura política de um grupo. Desenvolve laços de pertencimento. Ajuda na construção da identidade coletiva do grupo (este é um dos destaques da educação não-formal na atualidade); ela pode colaborar para o desenvolvimento da auto-estima e do empowerment do grupo, criando o que alguns analistas denominam, o capital social de um grupo. Fundamenta-se no critério da solidariedade e identificação de interesses comuns e é parte do processo de construção da cidadania coletiva e pública do grupo (GOHN, 2006, p. 30).

A proposta pedagógica, baseada na interdisciplinaridade, favorecia o fortalecimento da cultura política, dos laços de solidariedade e do empoderamento das crianças e dos

\section{POLÊM!CA $\mid$ LABORE}


adolescentes envolvidos no PCP. Os educadores sociais eram peças-chave para o êxito ou não dessas ações.

Para entender como a interdisciplinaridade estava presente nas atividades desenvolvidas pelo PCP, elegeu-se um dos temas desenvolvidos em 2007: Brincadeiras. Este teve como pergunta de partida: como as crianças de Mossoró se divertem hoje? Com esse tema gerador, cada um dos núcleos desenvolveu um projeto. O Núcleo de corpo, esporte e lazer trabalhou com o projeto Brincadeiras e o Núcleo de artes visuais, sonoras e cênicas, responsabilizou-se pelo desenvolvimento do projeto Brinquedos. Percebeu-se que a escolha do tema estava relacionada com algo bem presente na vida dos participantes do projeto, vindo a favorecer o estímulo à prática de pesquisas (PETROBRAS, 2008).

Inicialmente, os educadores realizaram um estudo sobre brinquedos e brincadeiras, para depois orientar as crianças e adolescentes na realização de uma pesquisa sobre a história dos brinquedos e das brincadeiras. Também assistiram filmes e documentários acerca das práticas de professores em contextos diversos e em situações de sala de aula, envolvendo os temas dos projetos. Após esse momento, os educadores fizeram um levantamento a respeito de como as crianças de Mossoró atualmente se divertem.

Os educadores planejaram diversas outras atividades que envolveram estudos sobre jogos, brinquedos e brincadeiras, estimulando as crianças e os adolescentes a discutir, por exemplo, as regras dos jogos. Ocorreu também, a sistematização dos tipos de brincadeiras e a apresentação do poema "Os brinquedos do vovô", de Rosalina Chiarion, com o uso de fantoches, conforme os registros do programa.

Com o intuito de promover a interação das crianças com a família e a comunidade, foi proposta uma roda lúdica onde pais e filhos tiveram a oportunidade de partilhar e comparar os tipos de brincadeiras em diferentes tempos. Nesse momento, tiveram a oportunidade de colocar em prática o que aprenderam da melhor forma: brincando. Posteriormente, dedicaramse ao processo de reescrita sobre as brincadeiras: seus nomes, como se brinca, quais suas regras, tendo em vista a publicação de um catálogo sobre como as crianças se divertiam. Também foi criado um grande painel, pintado em tecido, destacando essas brincadeiras. Esse trabalho serviu de cenário para a peça de teatro "Tudo é brincadeira", encenada no Teatro Municipal Dix-Huit Rosado, por ocasião do Festival de Teatro da UERN - FESTUERN.

\section{POLÊM!CA $\mid$ LABORE}


Já no desenvolvimento do projeto "Brinquedos" a meta foi a construção e exposição de brinquedos fabricados pelas crianças e os adolescentes sob orientação dos educadores sociais. Inicialmente, eles foram estimulados a representarem, em forma de desenho, o seu brinquedo preferido. Também foi lida em grupo uma das obras de Monteiro Lobato, “A pílula falante", a partir da qual os educadores suscitaram uma discussão sobre a história dos brinquedos, enfatizando a personagem Emília e os materiais que Tia Nastácia utilizou para construir essa boneca. Assim, fazia-se uma comparação entre os brinquedos de épocas anteriores e os da atualidade, bem como os materiais utilizados para sua fabricação (PETROBRAS, 2008).

As descobertas sobre a história dos brinquedos foi algo muito empolgante para as crianças, adolescentes e educadores do programa, principalmente os meninos. O interesse destes em conhecer a história da bola de futebol estimulou-os, como também aos educadores, a buscar informações na internet.

Após a elaboração de desenhos e de outras atividades, teve início o processo de construção de brinquedos. Para isso, foi promovido um intercâmbio com a Associação Comunitária Reciclando para a Vida (ACREVI), que trabalha com a reciclagem de resíduos sólidos. Nesses contatos, o público do PCP participou de palestras, recebeu o grupo de teatro da ACREVI no espaço onde ocorria o Programa e realizou uma campanha de coleta seletiva para a fabricação de brinquedos.

O trabalho desenvolvido na construção desses brinquedos foi revelando aos poucos a necessidade e a aquisição de conhecimentos sobre a utilização de régua, o efeito de um determinado tipo de tinta em diferentes materiais, as figuras geométricas, a ideia de ângulo e de linha, dentre outros. Finalizados os brinquedos, estes foram expostos em espaço aberto à visitação de escolas, familiares e comunidade em geral.

Em suma, vê-se no trabalho desenvolvido pelo PCP um significado educativo de grande vulto, uma vez que colocou crianças e adolescentes de bairros periféricos na condição de desenvolver as capacidades de pensar, produzir, publicar, interagir e intervir na comunidade, desafios estes extensivos aos profissionais e estagiários que orientavam os trabalhos junto às crianças e adolescentes atendidos. Nesta perspectiva, o PCP pode ser concebido como um espaço de construção permanente de conhecimentos, no qual os seus participantes adquirem alguns direitos básicos de cidadania.

\section{POLÊM!CA $\mid$ LABORE}




\section{Considerações finais}

O termo interdisciplinaridade tem ocupado grande espaço nos meios acadêmico e educacional nas últimas décadas. Em geral, isso ocorre quando são criados projetos envolvendo disciplinas diversas no interior da escola ou quando esta se envolve em projetos ou programas de cunho social com caráter de extensão, muitas vezes tendo à frente instituições de ensino superior e/ou empresas. Um exemplo disso é o Programa de Criança Petrobras (PCP) tratado neste artigo.

Nessas ações, entende-se que inclusão social e interdisciplinaridade podem e devem dialogar, visto que uma postura interdisciplinar exige autoconhecimento e empatia por parte do educador para com o educando. Da mesma maneira, para transformar o ambiente onde se desenvolvem as práticas educativas (seja a escola ou outro local) em um espaço acolhedor e inclusivo, faz-se necessário igual postura por parte do educador.

As considerações tecidas por Salgado e Souza (2017, p. 91) são esclarecedoras dessa relação: "Quando pensamos em um educador que apresenta uma atitude interdisciplinar, pensamos em um profissional acolhedor, que se descobre como parte de um processo de ensino e aprendizagem, e não como o único responsável/detentor do poder de conhecer”. Como asseguram essas autoras, há, em uma prática interdisciplinar, uma valorização do meio, do contexto, dos envolvidos e seus referenciais mais significativos.

Nessa direção, as experiências pedagógicas com educação não-formal no PCP revelam que, embora a interdisciplinaridade seja considerada um grande desafio, foi possível praticá-la a partir da intervenção pedagógica da Faculdade de Educação da UERN com os educadores sociais.

Entretanto, apesar desse avanço, são muitos os obstáculos para a realização de um trabalho da natureza proposta pelo PCP, configurando-se como o maior deles a formação pedagógica da equipe envolvida com seus projetos, haja vista que, ao se propor uma prática interventiva interdisciplinar, é necessário que sejam rompidas as ações educativas conteudistas e fragmentadas, fato que exige do educador uma postura que envolva o espírito investigador, a capacidade criativa e o trabalho em equipe.

Dessa forma, é necessário investir no processo de formação permanente dos profissionais e estagiários, proporcionando-lhes uma capacitação que inclua leituras, visitas a museus, bibliotecas, exposições, troca de experiências com outros programas, intercâmbio

\section{POLÊM!CA $\mid$ LABORE}


com outras instituições de ensino e grupos de pesquisa, de modo que superem as fronteiras disciplinares a que estão habituados. Somente assim, os educadores sociais envolvidos poderão ser capazes de inovar, variar suas técnicas de ensinar, buscar qualidade e não quantidades de conteúdo, e ter boa relação com o público envolvido de forma a contribuir para a formação cidadã desses sujeitos, possibilitando a construção do conhecimento e o desenvolvimento da sua autonomia.

\section{Referências}

BRASIL. Ministério da Educação. Secretaria de Educação Média e Tecnológica. Parâmetros Curriculares Nacionais: Ensino Médio. Brasília: Ministério da Educação, 2002.

FAZENDA, Ivani. A interdisciplinaridade: um projeto em parceria. São Paulo: Loyola, 1993.

Interdisciplinaridade: definição, projeto, pesquisa. In: FAZENDA, Ivani (Coord.). Práticas interdisciplinares na escola. 13. ed. São Paulo: Cortez, 2013.

FREIRE, Paulo. Pedagogia do oprimido. Rio de Janeiro: Paz e Terra, 1987.

GADOTTI, Moacir. A questão da educação formal/não-formal. Texto apresentado ao Institut International des Droits de L'enfant (IDE). Droit à l'éducation: solution à tous les problèmes ou problème sans solution? Sion, 2005. Disponível em:

<http://www.vdl.ufc.br/solar/aula_link/lquim/A_a_H/estrutura_pol_gest_educacional/aula_01/imagens/01/Educa cao_Formal_Nao_Formal_2005.pdf >. Acesso em: 23 jul. 2016.

GOHN, Maria da Glória. Educação não-formal e o educador social: atuação no desenvolvimento de projetos sociais. São Paulo: Cortez, 2010.

Educação não-formal, participação da sociedade civil e estruturas colegiadas nas escolas. Ensaio:

Avaliação de Políticas Públicas em Educação, Rio de Janeiro, v. 14, n. 50, p. 27-38, jan./mar. 2006.

Educação não-formal e cultura política: impactos sobre o associativismo do terceiro setor. São Paulo: Cortez, 1999.

LIBÂNEO, José Carlos. Pedagogia e pedagogos, para quê? 12. ed. São Paulo: Cortez, 2010.

PETROBRAS. Programa de Criança Petrobras. Relatório Mensal de Atividade, Mossoró, 2007.

Programa de Criança Petrobras. Plano de Trabalho, Mossoró, 2008.

SALGADO, Priscila Aparecida Dias; SOUZA, Mariana Aranha. A atitude interdisciplinar como proposta de acolhimento nos processos de inclusão escolar. Revista Interdisciplinaridade, São Paulo, n. 10, p. 81-93, 2017.

SEVERO; José Leonardo; PIMENTA, Selma Garrido. A Pedagogia entre o passado e a contemporaneidade: apontamentos para uma ressignificação epistemológica. Revista Inter Ação, Goiânia, v. 40, n 3, p. 477-492, dez. 2015.

Recebido em: 30/07/2016.

Aceito em: 11/05/2017.

\section{POLÊM!CA $\mid$ LABORE}

Polêmica - Revista Eletrônica da Uerj - Rua São Francisco Xavier, 524, $1^{\circ}$ andar

bloco D, sl.1001 • Tels.: +55 21 2334-4088/4087 • http://www.e-publicacoes.uerj.br/index.php/polemica/index

http://www.labore.uerj.br • laboreuerj@yahoo.com.br 